\title{
Identification of novel neuroendocrine-specific tumour genes
}

\author{
E Hofsli*, ${ }^{*, 2}$, TE Wheeler', M Langaas ${ }^{3}$, A Lægreid' and L Thommesen ${ }^{1,4}$ \\ 'Department of Cancer Research and Molecular Medicine, Faculty of Medicine, Norwegian University of Science and Technology, Trondheim, Norway; \\ ${ }^{2}$ Oncology Unit, St Olavs Hospital HF, Trondheim, Norway; ${ }^{3}$ Department of Mathematical Sciences, Norwegian University of Science and Technology, \\ Trondheim, Norway; ${ }^{4}$ Department of Food and Medical technology, Sør-Trøndelag University College, Trondheim, Norway
}

Neuroendocrine tumours (NETs) comprise a heterogenous group of malignancies with an often unpredictable course, and with limited treatment options. Thus, new diagnostic, prognostic, and therapeutic markers are needed. To shed new lights into the biology of NETs, we have by cDNA transcript profiling, sought to identify genes that are either up- or downregulated in NE as compared with non-NE tumour cells. A panel of six NET and four non-NET cell lines were examined, and out of 12743 genes examined, we studied in detail the 200 most significantly differentially expressed genes in the comparison. In addition to potential new diagnostic markers (NEFM, CLDN4, PEROX2), the results point to genes that may be involved in the tumorigenesis (BEXI, TMEPAI, FOSLI, $R A B 32)$, and in the processes of invasion, progression and metastasis (MME, STAT3, DCBLD2) of NETs. Verification by real time qRT-PCR showed a high degree of consistency to the microarray results. Furthermore, the protein expression of some of the genes were examined. The results of our study has opened a window to new areas of research, by uncovering new candidate genes and proteins to be further investigated in the search for new prognostic, predictive, and therapeutic markers in NETs.

British Journal of Cancer (2008) 99, I330-1339. doi:I0.1038/sj.bjc.6604565 www.bjcancer.com

Published online 30 September 2008

(C) 2008 Cancer Research UK

Keywords: neuroendocrine tumours; gene expression; microarray; neuroendocrine markers; cell lines

Neuroendocrine (NE) tumours (NETs) belong to a heterogenous group of neoplasms arising from malignant transformation of various types of NE cells (Falkmer, 1993; Wick, 2000; DeLellis, 2001; Hofsli, 2006). Although the majority of NETs are rather slow growing, their biology is often unpredictable, making their management a great challenge (Stephenson, 2006; Vilar et al, 2007). Thus, new insight into the biology of these fascinating tumours could not only make prognostication easier, but also guide in the selection for the right treatment strategy, and contribute in the search for new drug targets. This last issue is of vital importance, as up till now, only surgery has the potential to cure patients with NET disease.

Prediction of the biological behaviour of NETs may be difficult based upon histological criteria alone (Wick, 2000; Stephenson, 2006). Well-differentiated NETs are easily recognised by routine tissue staining and conventional light microscopical (LM) examination, combined with immunohistochemical (IHC) detection of NE markers such as chromogranin A (CHGA) and synaptophysin (SYP). However, dealing with poorly differentiated tumours, it may be difficult to decide whether a tumour exhibits an NE character. Thus, new diagnostic markers are warranted.

In addition to classical NETs, it has been increasingly recognised that both mixed endocrine-exocrine malignant tumours, as well as NE differentiation in common epithelial cancers, may occur (Capella et al, 2000; Sørhaug et al, 2007). The picture is even more complex, as recent research has indicated that use of more

*Correspondence: Dr E Hofsli, Oncology Unit, St Olavs University Hospital HF, Olav Kyrresgt. 17, N-7006 Trondheim, Norway;

E-mails: eva.hofsli@stolav.no or eva.hofsli@ntnu.no

Received 27 June 2008; accepted 21 July 2008; published online 30 September 2008 sensitive methods such as the tyramide signal amplification technique, will identify more NE tumour cells than today's routine diagnostic procedures manage to do (Sørhaug et al, 2007). With respect to prognosis and treatment, the impact of such NE differentiation in epithelial cancers is mostly unknown.

To shed new lights into the biology of NETs, we have compared the gene expression pattern of a selection of NE tumour cells, with that of a group of non-NE tumour cells. By this approach, we have identified genes that are differentially expressed in NE $v s$ non-NE tumour cells. We propose that some of the genes and their gene products may represent interesting new molecular factors with regard to tumorigenesis, prediction of prognosis and treatment response, as well as may represent novel therapeutic targets.M

\section{MATERIALS AND METHODS}

\section{Cell culture}

Six NE and four non-NE cell lines were used in the gene expression analysis. All cell lines, except the BON cell line, were obtained from the American Type Culture Collection (ATCC, Manassas, VA, USA). BON cells (Evers et al, 1991) were a generous gift from Professor Kjell Öberg, Department of Medical Science, Uppsala University Hospital, Uppsala, Sweden, and cultured as described in Hofsli et al (2005). The six NE cell lines represent various NETs: neuroblastomas (SK-N-AS, SK-N-FI), bronchial carcinoids (NCIH727, UMC-11), gastrointestinal carcinoid (BON), and medullary thyroid carcinoma (TT). The non-NE cell lines were colorectal adenocarcinomas (WiDr, SW480), lung adenocarcinoma (A-427) and glioblastoma (A-172). All these cell lines were cultured according to the requirements given by ATCC. 


\section{Isolation of RNA}

Cells were cultured in $75 \mathrm{~cm}^{2}$ culture flasks until $80 \%$ confluence, harvested and directly subjected to RNA isolation. Total RNA was isolated using RNeasy midi kit (Qiagen, Germantown, MD, USA), according to the manufacturer's instruction. Two independent biological experiments were performed with each cell line. The quality of the RNA was examined by use of Agilent 2100 Bioanalyzer (Agilent Technologies, Palo Alto, CA, USA). The samples were kept frozen at $-80^{\circ} \mathrm{C}$ until further processing.

\section{Microarray hybridisation}

Human cDNA arrays with 15000 probes in duplicate were obtained from Norwegian Microarray Consortium, Oslo, Norway (http://www.microarray.no). These arrays were prepared using sequence-verified human genes (Research Genetics, Huntsville, $A L, U S A)$. Additional information of cDNA clone preparation and printing is described in detail within the platform GPL3313, of the Gene Expression Omnibus (http://www.ncbi.nlm.nih.gov/geo/ query/acc.cgi?acc $=$ GPL3313). Two negative controls and ten different cDNA spike-in controls from Arabidopsis thaliana (Stratagene SpotReporter, La Jolla, CA, USA) were included in all arrays. Total RNA ( $2 \mu \mathrm{g})$ from the cell lines and from Universal Human Reference RNA (Stratagene, La Jolla, CA, USA), was reverse transcribed and labelled with $\mathrm{Cy} 3-$ and $\mathrm{Cy} 5$-attached dendrimer, respectively, using the Genisphere 3DNA Array 350 Expression Array Detection kit (Genisphere, Montvale, NJ, USA), as described in the manufacturer's protocol and previously by us (Yadetie et al, 2003; Nørsett et al, 2004; Hofsli et al, 2005). To reduce the artefacts because of different sensitivity to photobleaching, the biologic replicates of each of the 10 cell lines were randomised by dye-swaps. The arrays were scanned separately by two wavelengths (532 and $633 \mathrm{~nm}$ ) using ScanArray Express HT scanner (Packard BioScience, Billerica, MA, USA).

\section{Microarray data analysis}

The microarray data were prepared according to the MIAME recommendations (Brazma et al, 2001). Image analysis was carried out using the GenePix Pro 4.1 software (Axon Instruments, Union City, CA, USA). All subsequent statistical analysis was performed using the statistical package R (R Development Core Team, 2004), and the LIMMA package from the Bioconduction project (Smyth,
2005). Flawed spots (manually examined) and spots with more than $40 \%$ saturated pixels in any channel were removed from the analyses. This resulted in the removal of $17-31 \%$ of spots for each array. To compensate for systematic errors each array was normalised using loess normalisation, and then scaled so that the log-transformed ratios had the same median absolute deviation (Yang et al, 2002a,b). Further analyses were based on these normalised log-transformed ratios for each duplicate gene for the 20 microarrays.

To assess the difference between the NE $v s$ non-NE tumour cells for each gene, tests for differential expression were performed using moderated $t$-tests based on duplicated spots, as implemented in the Limma R package of Smyth et al (2005). This is based on empirical Bayes analysis, where the power of the tests is improved by replacing gene-specific variance estimates with estimates found by borrowing strength from data on the remaining genes. The proportion of truly differentially expressed genes was estimated using the convex decreasing density estimator of Langaas (2005), and the false discovery rate (FDR) was estimated using the method of Storey (2002), with the estimated proportion of truly differentially expressed genes found above inserted.

Cluster analysis was performed as an aid to display the results in a graphical manner. The analysis was performed on the normalised log ratios taking the median over duplicate spots for each gene, and the mean over the dye-swapped replicates. Hierarchical cluster analysis was based on Pearson correlation and the distance between the clusters was both computed using the average- and complete linkage. In addition clustering using the K-means algorithm (using two clusters) was also performed on a selection of the most differentially expressed genes.

\section{Real-time qRT - PCR}

cDNA synthesis was performed with $500 \mathrm{ng}$ total RNA in a $10-\mu \mathrm{l}$ reaction containing $1 \times$ PCR buffer II, $5 \mathrm{mM} \mathrm{MgCl}_{2}, 500 \mu \mathrm{M}$ each dNTP, $2.5 \mu \mathrm{m}$. Oligo $\mathrm{d}(\mathrm{T}) 16$ primer, $0.4 \mathrm{U} / \mu \mathrm{l}$ RNase inhibitor and $2.5 \mathrm{U} / \mu \mathrm{l} \mathrm{MuLV}$ Reverse transcriptase (Applied Biosystems, Mannheim, Germany). cDNA synthesis was performed at $10 \mathrm{~min}$ at $25^{\circ} \mathrm{C}$ followed by $1 \mathrm{~h}$ at $48^{\circ} \mathrm{C}$ and $5 \mathrm{~min}$ at $95^{\circ} \mathrm{C}$. Design of PCR primers and probes was performed using Primer3 (version 0.2, online software) (http://frodo.wi.mit.edu/cgi-bin/primer3/ primer3_www.cgi) and the mRNA sequences obtained using the NCBI RefSeq accession numbers of the respective genes (Table 1). All primers and probes were delivered from Eurogentec, Seraing,

Table I Primers and probes

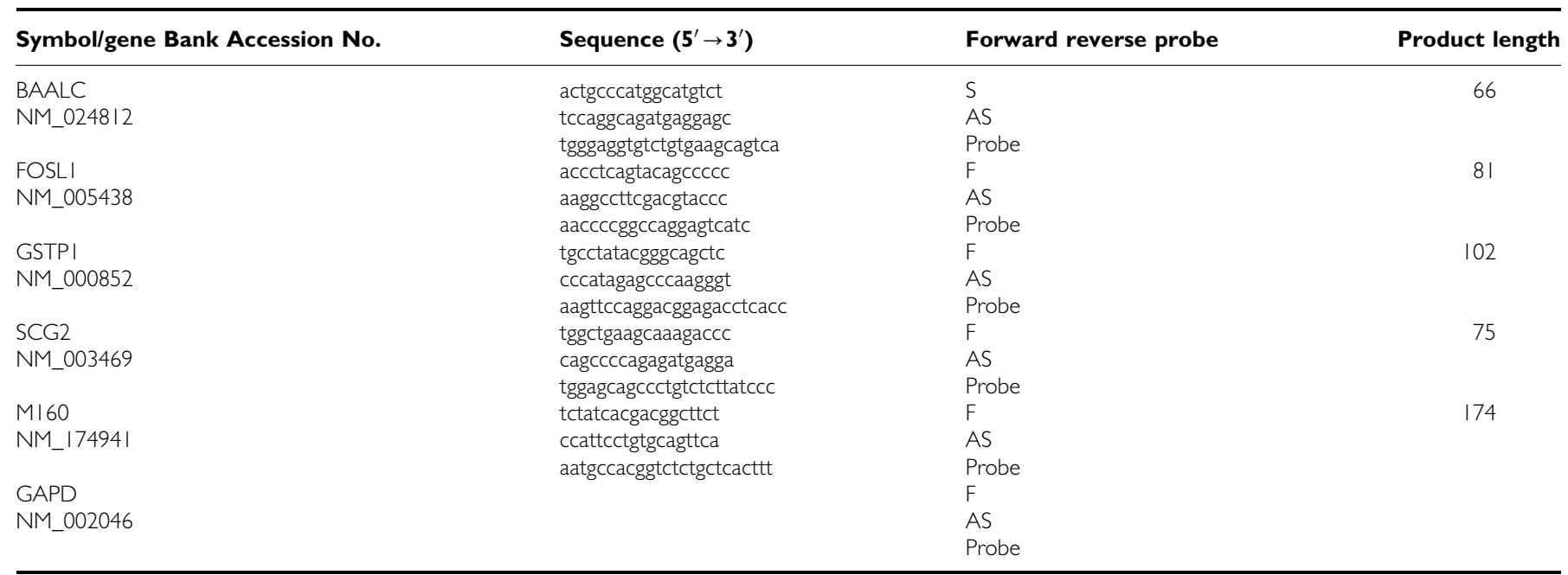

Genes, primers, and probe sequences of selected genes for confirmation studies. The length, product length, and orientation are given here. 
Belgium, and had an optimal annealing temperature of 56 and $68^{\circ} \mathrm{C}$, respectively. TaqMan real-time PCR was performed with $1 \times$ Quantitect Probe PCR Master Mix (Qiagen, Germantown, MD, USA), $400 \mathrm{~nm}$ of each primer, $200 \mathrm{~nm}$ TaqMan Probe (Eurogentec) or sybergreen and cDNA equivalent to $62.5 \mathrm{ng}$ total RNA in a total reaction volume of $25 \mu \mathrm{l}$. The Real-Time PCR was performed in Stratagene's Mx3000P Real Time PCR system; $15 \mathrm{~min}$ at $95^{\circ} \mathrm{C}, 40$ thermal cycles of $15 \mathrm{~s}$ at $94^{\circ} \mathrm{C}, 30 \mathrm{~min}$ at $56^{\circ} \mathrm{C}$ and $30 \mathrm{~s}$ at $76^{\circ} \mathrm{C}$. Each sample was measured in triplicate. A negative control without the cDNA template was included, and contamination by genomic DNA was ruled out by performing PCR analysis on template where reverse transcriptase had been omitted in the $\mathrm{RT}$ reactions. GAPDH was run in parallel as controls to monitor RNA integrity and to be used for normalisation. Fold induction of gene expression level was estimated by the $\Delta \Delta C_{\mathrm{t}}$-method, where: Fold change $=2^{-\Delta \Delta \mathrm{C} t}$ and $\Delta \Delta C_{\mathrm{t}}=\left(C_{\mathrm{tGOI}}-C_{\mathrm{tGAPDH}}\right)_{\text {untreated }}-\left(C_{\mathrm{tGOI}}-\right.$ $\left.C_{\mathrm{tGAPDH}}\right)_{\text {treated }}$ (Livak and Schmittgen, 2001). This was accomplished by using the same universal human reference RNA in both the microarray and the real-time RT-PCR analysis;

$$
2^{-\left(C_{\mathrm{t}_{\mathrm{GENX}}}-C_{\mathrm{t}_{\mathrm{GAPHD}}}\right) \text { cell line- }-\left(C_{\mathrm{t}_{\mathrm{GENX}}}-C_{\mathrm{t}_{\mathrm{GAPHD}}}\right) \text { HumRef }}
$$

\section{Western blot}

Whole cell lysates were prepared from 5-7 $\times 10^{6}$ cells which were washed two times in PBS, scraped and harvested directly in $2000 \mu \mathrm{l}$ SDS-sample buffer (62.5 mM Tris- $\mathrm{HCl}, \mathrm{pH} 6.8 ; 8.7 \%$ glycerol; $2 \% \mathrm{w} / \mathrm{v}$ SDS; $5 \% \mathrm{v} / \mathrm{v} 2-\beta$ mercaptoethanol; $0.09 \% \mathrm{w} / \mathrm{v}$ bromophenol blue). Viscosity was reduced by drawing the suspension through a $21-\mathrm{G}$ needle, cell debris were removed by centrifugation $(15000 \mathrm{~g}$, $10 \mathrm{~min}$ ), and the supernatant was stored at $-80^{\circ} \mathrm{C}$. Each extract $(15 \mu \mathrm{l})$ was boiled and separated on an SDS $10 \%$ polyacrylamide gel (running buffer: $25 \mathrm{~mm}$ Tris- $\mathrm{HCl}, \mathrm{pH} 8.3 ; 190 \mathrm{~mm}$ glycine, $0.1 \%$ $\mathrm{w} / \mathrm{v}$ SDS) before electrotransfer onto Hybond-P membranes (Amersham Pharmacia Biotech, Pittsburgh, PA, USA). The transfer was performed in $25 \mathrm{~mm}$ Tris- $\mathrm{HCl}, 190 \mathrm{~mm}$ glycine and $20 \%$ methanol, $\mathrm{pH} 8.3$, for $1 \mathrm{~h}$ at $175 \mathrm{~mA}$. The membranes were treated with $5 \%$ nonfat dry milk (Nestlé, Vevey, Switzerland) in TBS (50 mM Tris- $\mathrm{HCl}, \mathrm{pH} 7.5$ and $150 \mathrm{~mm} \mathrm{NaCl}$ ) for $1 \mathrm{~h}$ at room temperature and incubated with primary antibodies diluted $(1: 500-1: 1000)$ in TBS with $1 \%$ BSA and $0.05 \%$ Tween 20 for $2 \mathrm{~h}, 20^{\circ} \mathrm{C}$. The blots were then incubated with peroxidaseconjugated secondary antibodies $(1: 1000)$ in TBS with $1 \%$ BSA and $0.05 \%$ Tween 20 for $1 \mathrm{~h}$ at room temperature. After washing $(4 \times 15 \mathrm{~min}$ in TBS with $0.05 \%$ Tween 20$)$, binding of secondary antibodies was visualised by the ECL-detection system (Amersham) before they were digitally exposed with the KODAK Image Station 2000R (Kodak, Rochester, NY, USA) for $5 \mathrm{~min}$. GAPDH levels were used to verify protein loading.

The following antibodies were used: mouse anti-human GAPDH $(1: 1000)$ (Abcam, Cambridge, UK), mouse anti-human PRDX2 $(1: 1000)$ (Abcam), rabbit anti-human HPN (1:1000) (Cayman, Michigan, USA), rabbit anti-human SCG2 (1:500) (Abcam) and a secondary antibody conjugated to horseradish peroxidase (Pierce, Rockford, IL, USA).

\section{Immunohistochemical and ultrastructural examinations}

For IHC investigations, cell pellet was conventionally fixed in $10 \%$ neutral formalin, dehydrated, and embedded in paraffin. Sections, about 4-5 micron thick, were employed for the IHC examinations, using the Vectastain ABC kit (Vector Lab., Burlingame, CA, USA), and/or Tyramide signal amplification technique (NEN LifeScience Products, Boston, MA, USA), as previously described (Qvigstad et al, 1999). Chromogranin A antiserum (1:500) was provided by Incstar (Stillwater, MN, USA), monoclonal mouse antisynaptophysin antiserum $(1: 20)$ by Dako (Glostrup, Denmark), anti rat neuron-specific enolase $(1: 500)$ by Polysciences (Warrington, PA, USA), and antineurofilament $M(1: 4000)$ by Fitzgerald (MA, USA).

For the electron microscopic (EM) investigations, the pellet was fixed in $2 \%$ neutral glutaraldehyde, post-fixed in $2 \%$ osmium tetroxide, contrasted with $1 \%$ lead citrate and $4 \%$ uranyl acetate, and conventionally embedded in Epon. Finally, conventional ultra thin sections were cut and analysed by means of our transmission EMs (JEOL 100CX and Phillips SEI Tecnai 12).

\section{RESULTS}

\section{Confirmation of the NE character}

To confirm the NE and non-NE character of the cell lines, respectively, IHC and EM investigations were performed in addition to conventional LM examination. The employed NE cell lines (NCI-H727, UMC-11, SK-N-AS, SK-N-FI, TT, BON) encompass NE features with the expression of CHGA and SYP as the confined NE marker. The four cell lines known to be of non-NE character (WiDr, A-172, A-427, SW480), showed no staining with CHGA and SYP (data not shown). In addition, the cells were examined for the expression of ENO2 (enolase 2/neuron-specific enolase), an NE marker thought to be less specific than the conventional NE markers CHGA and SYP. All the presumed NE cell lines showed positive immunoreactivity to enolase 2 , and this was also the case for the non-NE cell lines A-427 and SW480 (data not shown). EM investigations demonstrated occurrence of typical $\mathrm{NE}$ secretion granules in all the NE tumour cells, but not in any of the non-NE tumour cells, thus confirming the predefined $\mathrm{NE} /$ non-NE characteristics of the cell lines used.

\section{Genes differentially expressed in NE $v s$ non-NE tumour cells}

Having confirmed the NE and non-NE character of the cell lines, respectively, we performed transcript profiling by cDNA microarray analysis in an effort to identify new NE-specific genes, and by this, get more insight into the biology of NETs.

By using the convex decreasing density estimator for the proportion of true null hypotheses as presented in Langaas (2005), we expect $5.5 \%$ of the genes studied to be differentially expressed in NE vs non-NE cells. The 200 most significant genes ( $P$-value $0.008 / F D R \quad 0.49$ ) in the comparison of the NE $v s$ non-NE tumour cell groups are sequence verified, and 153 genes are given as Supplementary Information in the gene expression omnibus (GEO) GSE4328.

Based on information from the GO annotation database and literature search, these genes are displayed with the log ratio and biological processes in which they are likely to be involved. The up- and downregulated genes range from $\log _{2} 5.87$ to -2.92 , respectively. The 70 most highly up- and downregulated genes, are shown in Table 2. A hierarchical cluster analysis of the 48 most significantly differentially expressed genes ( $P$-value $0.0014 / \mathrm{FDR}$ 0.2823 ) are shown in Figure 1.

The three most highly overexpressed genes: SCG3 (26.6 fold), SCG2 (15.3 fold) and DDC (9.6 fold) (Table 2), have previously been shown to be linked to NE tumour biology, thus confirming the reliability of our study design. SCG3 and SCG2 are both members of the chromogranin-secretogranin family of $\mathrm{NE}$ secretory, acidic glycoproteins (Taupenot et al, 2003), and DDC has more recently been shown to be expressed in various NETs (Uccella et al, 2006). Furthermore, the high expression of MAOA in our study, support previous findings of high expression of monoaminoxidase A in various NETs (Örlefors et al, 2003).

NETs in general are relatively slow growing tumours with a less invasive character than many epithelial cancers. Several genes thought to play a role in the processes of invasion, tumour 
Table 2 Differentially expressed genes in NE vs non-NE tumour cells

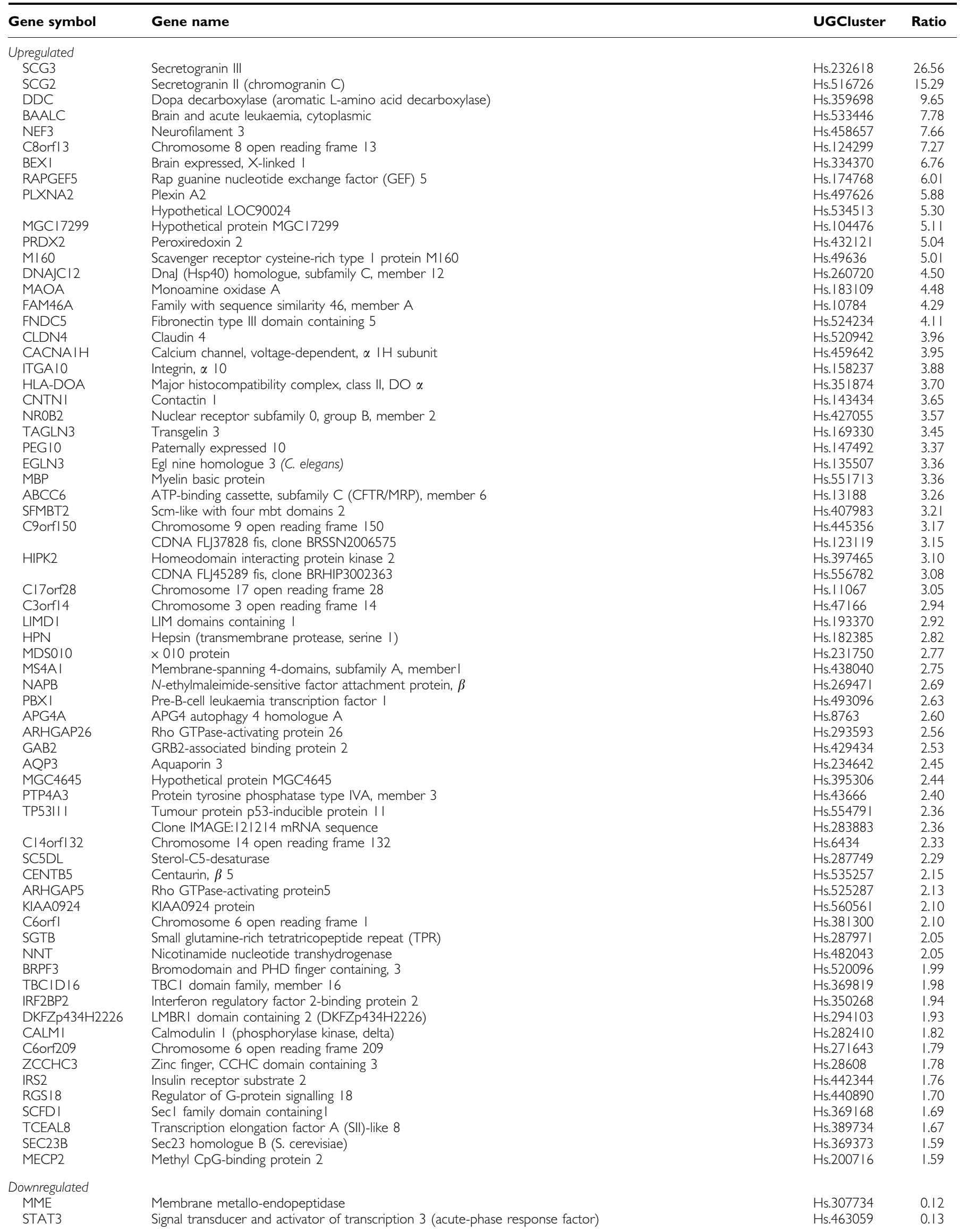


Table 2 (Continued)

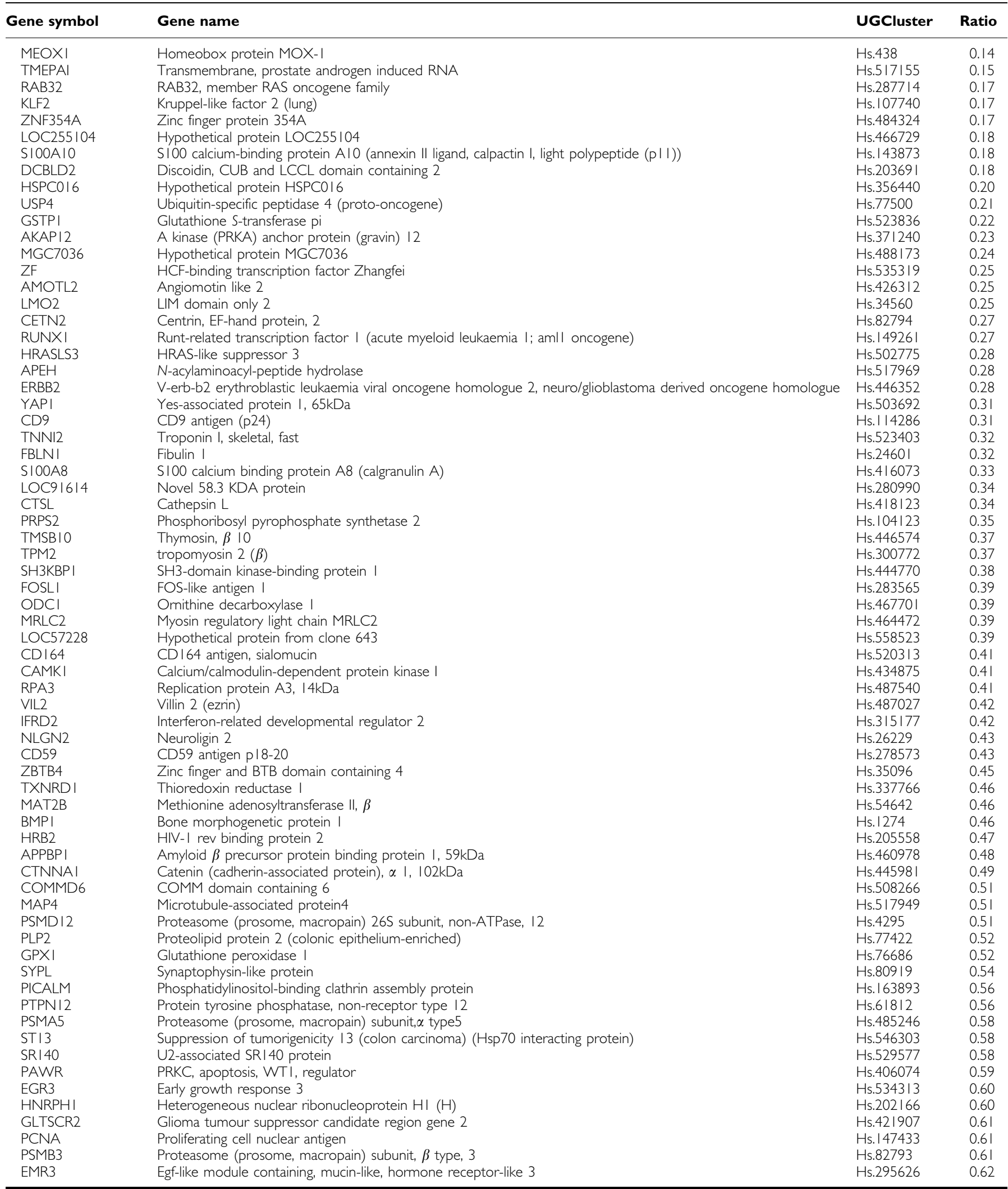

Genes significantly $(P<0.007)$ up- or downregulated in the neuroendocrine cell lines compared with the non-neuroendocrine cell lines. The first half of the table shows downregulated genes whereas the last part of the table shows the upregulated genes. The genes are all given with unigene cluster id's, official gene name and symbols in addition to their respective ratio (NE vs non-NE). 


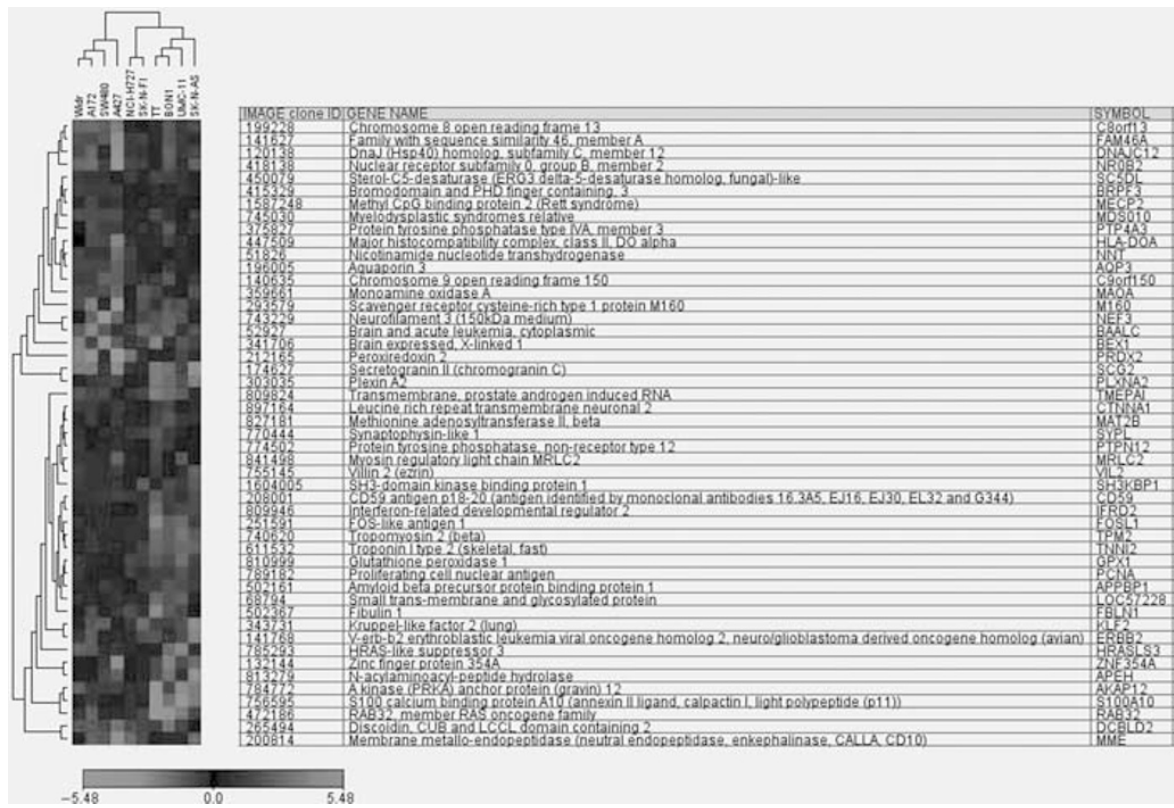

Figure I Hierarchical clustering analysis. A hierarchical clustering algorithm was used to cluster experimental samples on the basis of similarities of gene expression. Relationships between the experimental samples are summarised as dendrograms, in which the pattern and length of the branches reflect the relatedness of the samples (NE vs non-NE). Data are presented in a matrix format: each row represents a cDNA clone (identified with UniGene gene symbol, name and IMAGE clone id) and each column an individual mRNA (average gene expression log ratio) sample of NE (BON, TT, SK-N-AS, SK-NFI, $\mathrm{NCl}-\mathrm{H} 727, \mathrm{UMC}-\mathrm{II}$ ) and non-NE (WiDr, A- 172, SW480, A-427) cells. The results presented represent the ratio of hybridisation of fluorescent cDNA probes prepared from each experimental mRNA sample to a reference mRNA sample. These ratios (log) are a measure of relative gene expression in each experimental sample and were depicted according to the colour scale shown at the bottom.

progression and metastasis (MME, STAT3, DCBLD2, S100A10, $C D 9, S 100 A 8)$ were highly downregulated in the NE $v s$ the non-NE tumour group (Table 2 and Supplementary Information). The three most highly downregulated genes in our study were $M M E$ (0.12 fold), STAT3 (0.13) and DCBLD2 (0.14 fold). Our results also point to differences in expression of several genes thought to be involved in the process of tumorigenesis (BEX1, TMEPAI, FOSL1, $R A B 32, E R B B 2$ ) (Table 2 and Supplementary Information). Welldifferentiated NETs are in general relatively insensitive to various chemotheurapeutic drugs, and thus it is interesting to note variations between the two groups in the expression of genes known to be involved in the process of drug resistance (STAT3, PRXD2 ABCC6, GSTP1) (Table 2 and Supplementary Information). Nearly $50 \%$ of the upregulated, and $16 \%$ of the downregulated genes are in the GO database defined as having an unknown function (Supplementary Information).

\section{Validation by real-time $\mathrm{qRT}-\mathrm{PCR}$}

To validate the microarray results, we performed real-time quantitative RT-PCR analysis of five selected genes using the same RNA samples as those used in the microarray analysis. The selection of the genes (BAALC, SCG2, GSTP1, FOSL1, M160) were based upon a combination of $P$-value, differential expression, and biological function. In general, $70 \%$ of the genes found to be differentially expressed in the microarray study were confirmed by RT - PCR (Figure 2). This seems to be in accordance with previous studies using cDNA arrays (Kothapalli et al, 2002; Hofsli et al, 2005), and underlines the need to verify microarray data by additional methods.

\section{Protein expression analysis}

To investigate whether the difference in gene expression level was followed by a similar expression pattern at the protein level, we first performed western blot analysis of cell lysates. The selection of gene products analysed (secretogranin II, peroxiredoxin 2, hepsin) was based upon a combination of the expression level found in the microarray analysis, biological relevance, and availability of antibodies. As seen in Figure 3, the protein expression of the NE marker secretogranin II, correlated well with the gene expression level of SCG2 found in the microarray analysis (15-fold upregulated)(Table 2), and in the real-time RT-PCR analysis (Figure 2). All the NE tumour cell lines express a high level of SCG2, whereas the expression level in the non-NE cell group is almost undetectable. Hepsin (2.8 fold upregulated in the microarray analysis) was found to be expressed in all cell lines and without any significant difference in NE $v s$ non-NE cells (Figure 3). Thus, hepsin is ruled out as a possible new diagnostic marker of NET disease. On the contrary, the level of peroxiredoxin 2 expression (5 fold upregulated in the microarray analysis) was significantly different in the two groups (Figure 3). Peroxiredoxin 2 was clearly detectable in the NE cell line group, but almost undetectable in the non-NE cell group, thus pointing out peroxiredoxin 2 as an interesting new NE biomarker. The difference in secretogranin II and peroxiredoxin 2 expression was also confirmed by IHC analysis (data not shown).

In addition to secretogranin II and peroxiredoxin 2, our study points to NEFM as another interesting candidate marker of NET disease. NEFM, which was upregulated by a factor of 7.7 in the microarray analysis (Table 2), was by IHC shown to be expressed only in the NE tumour cells group (data not shown).

\section{DISCUSSION}

Although last year's genomic and proteomic research have uncovered some genes and gene products thought to have an important function in the context of NE tumour biology (Hofsli, 2006), still much is unknown concerning which factors that are important with regard to the causes and behaviours of NET 

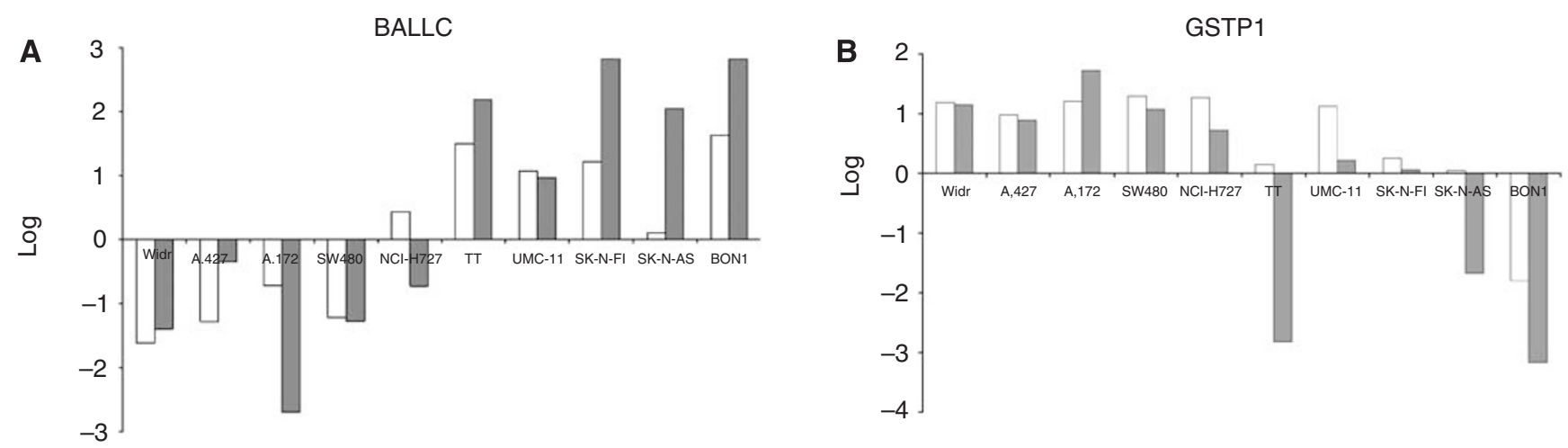

FOSL1
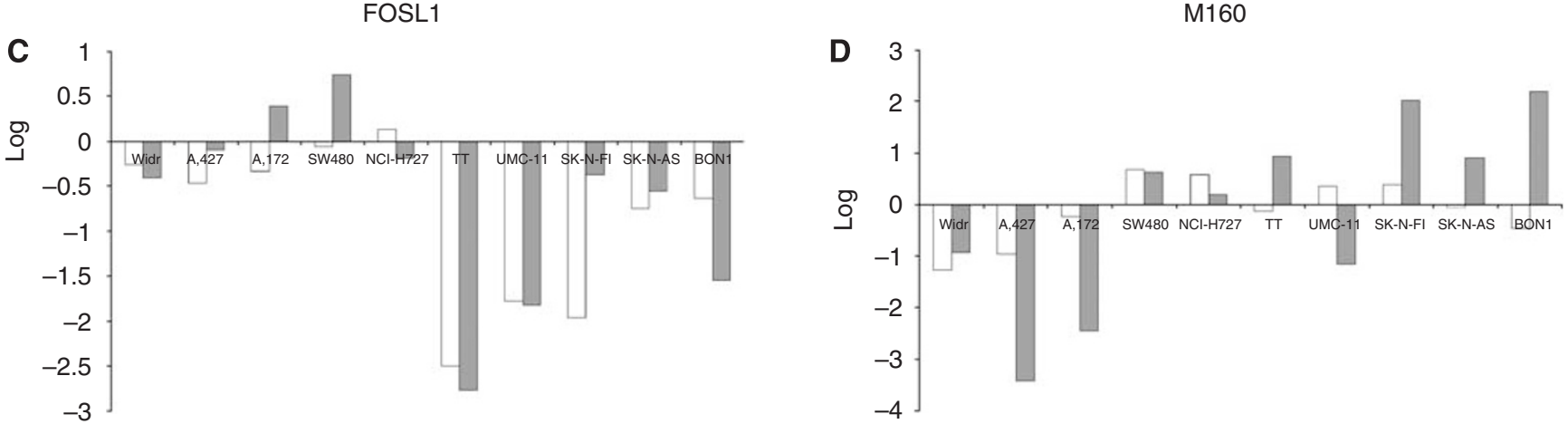

SCG2

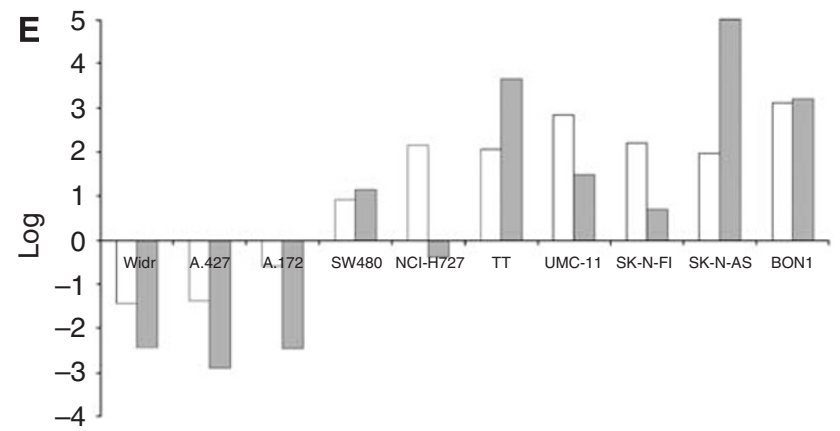

Figure 2 RT-PCR confirmation of microarray results. A selection of genes ( $\mathbf{A}-\mathbf{E}$ ) was also analysed by semi quantitative real-time RT-PCR (grey), and compared to the respective ratios of the microarray analysis (white). The two methods correlated at $9 / 10$ cell lines at best, and the lowest correlated at $6 / 10$ cell lines. $Y$ axis shows the log-transformed ratio of both the microarray and the RT-PCR, based on the fold change ratios and the delta-delta $C_{t}$ calculation, respectively.

diseases. The results of this study contribute to an increased insight into the biology of these tumours, by identifying genes that are differentially expressed in NE tumour cells as compared with non-NE tumour cells. We believe that some of these genes and gene products represent interesting candidates in the search for new prognostic, predictive and therapeutic markers. The study also point to genes that may play a role in the tumorigenesis of NETs.

The three most highly overexpressed genes in the NE $v s$ the non-NE tumour cell group (SCG3, SCG2 and DDC) (Table 2), have all previously been described in the context of NE tumour biology, thus confirming the reliability of our study design. Although secretogranin II and one of its split product (Taupenot et al, 2003; Guillemot et al, 2006) have been shown to be expressed in various types of NETs, investigations of the expression of secretogranin III in NETs have so far not been reported. The enzyme dopa decarboxylase (DDC)(catecholamine biosynthesis) has more recently been shown to be expressed in various NETs, such as bronchial carcinoids and poorly differentiated NE carcinomas of the lung (Uccella et al, 2006). It has also been shown to be a marker of neuroblastoma in children (Bozzi et al, 2004), and of NE differentiation in prostate carcinoma (Wafa et al, 2007). Another gene known to be involved in catecholamine metabolism, MAOA (Toninello et al, 2006), was also identified as highly expressed in the NET group (Table 2), a finding that was confirmed by IHC analysis (not shown). This supports previous findings demonstrating a high expression of MAOA in gastroenteropancreatic (GEP) tumours (Örlefors et al, 2003). To conclude, we believe that SCG3, SCG2 and DDC could represent useful additional biomarkers in NET diseases, and that they perhaps should be implemented in the standard diagnostic panel of NE biomarkers. Furthermore, measurement of MAOA activity may, as recently shown in a baboon model, aid in understanding the pathophysiology of NETs (Murthy et al, 2007). 


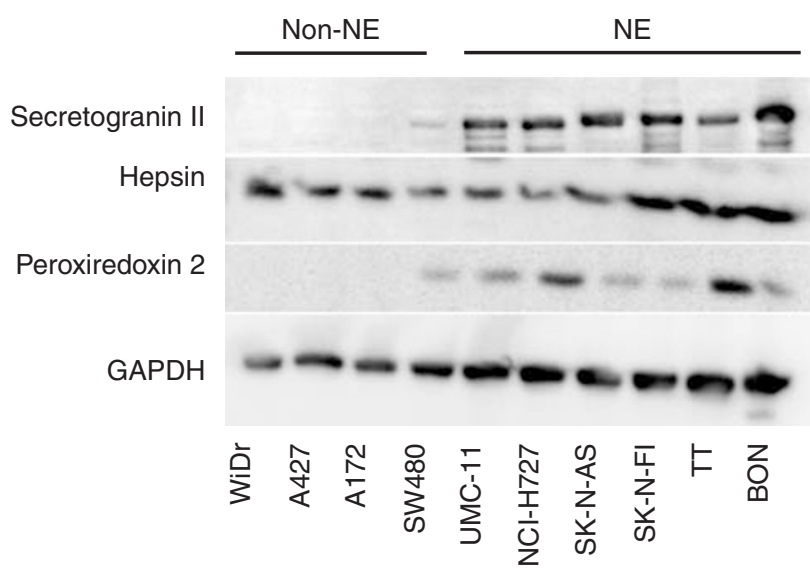

Figure 3 Western blot. Western blot analysis was performed on cell lines (NE and non-NE) with the antibodies against secretogranin II, hepsin, peroxiredoxin 2 and GAPDH. Cells were harvested and prepared as described in Materials and methods.

In addition to these above-mentioned potentially important NET biomarkers, our study points to NEFM, PRDX2, and CLDN4 as other interesting candidate markers of NET disease. The finding of an upregulation of the NEFM gene (a marker of neuronal differentiation) is in accordance to findings by Perez et al (1990), who found NEFM expression in a subset of pancreatic islet cell and rectal carcinoid tumours, although rarely in ileojejunal carcinoid tumours. Thus, the message brought from our study and that of Perez is, that neurofilament subtyping could well become a potential diagnostic tool with regard to NETs.

Also the antioxidant enzyme peroxiredoxin 2 (PRXD2) (antiapoptosis) was highly upregulated in the NE tumour cell group. PRXD2 was previously shown to be elevated in several human cancers, to confer resistance to chemo- and radiation therapy, and to promote tumour progression and metastasis (Lee et al, 2007). The tight junction protein claudin 4 (CLDN4) is also frequently overexpressed in several cancers, and is thought to represent a promising target for cancer detection, diagnosis, and therapy (Morin, 2005; Kominsky et al, 2007). A loss of claudin 4 expression at the invasive front in colorectal cancer correlates with cancer invasion and metastasis (Ueda et al, 2007), and thus the finding in our study of a rather high level of CLDN4 in the NE tumour group, may reflect NETs in general lower malignant phenotype. However, our results are in contrast to that of Moldvay et al (2007), who more recently have demonstrated that a majority of bronchial carcinoids express a lower level of CLDN4 than other histological types of primary bronchial cancers.

Several of the differentially expressed genes turned out to have unknown functions (Supplementary Information; GEO GSE4328). We focused on BAALC (brain and acute leukaemia, cytoplasmic), as a high mRNA transcript level of this gene has been found in tissues of neuroectodermal origin (Tanner et al, 2001), and has been shown to be an independent adverse prognostic factor in various acute leukaemias (Marcucci et al, 2005; Baldus et al, 2007). The high expression of BAALC found in the microarray analysis (Table 2), was confirmed by real-time PCR analysis (Figure 2).

Our results also point to differences in expression of several genes thought to be involved in the process of tumorigenesis (BEX1, TMEPAI, FOSL1, RAB32, ERBB2) (Table 2; Supplementary Information). One interesting find is the high expression of the novel BEX1 gene (brain expressed, X-linked 1) in the NE tumour cell group (Table 2). Previous studies have revealed a high expression of this gene in brain, but also in peripheral organs such as liver, pancreas, testis, and ovary (Yang et al, 2002a, b; Alvarez et al, 2005). It has more recently been suggested that BEX1 may play a role as a tumour suppressor in malignant glioma (Foltz et al, 2006). A very low expression was observed for the TMEPAI gene (Table 2), which is involved in androgen receptor signaling, and is proposed to play a role in prostate tumorigenesis (Xu et al, 2003). TMEPAI has been shown to be overexpressed in various solid tumours, probably because of abnormal activation of the EGF pathway (Giannini et al, 2003). Also the oncogenic transcription factor FOSL1, was downregulated in the NE tumour cell group. FOSL1 is upregulated in several solid cancers, and is becoming a new target for cancer intervention (Young and Colburn 2006). The ras family member $R A B 32$, has been proposed to represent a component of the oncogenic pathway of microsatellite instabilityhigh gastrointestinal adenocarcinomas (Shibata et al, 2006). In our study, RAB32 was highly downregulated in the NE $v s$ the non-NE group. Also the ERBB2 gene expression level was significantly lower in the NE tumour cell group than in the non-NET group. The expression level of this member of the oncogenic EGF receptor family, has previously been reported as a variable in various NETs (cf. Hofsli, 2006). So far, there is no strong evidence that ERBB2 amplification/overexpression could play an important role in NET pathogenesis, or that it could be a potential target for treatment, as is the case in various epithelial cancers (Hsieh and Moasser 2007). To conclude, our study is the first to reveal the expression pattern of BEX1, TMEPAI, FOSL1, and RAB32 in NE tumour cells, and we believe that they represent interesting novel candidates in the context of NET tumorigenesis.

A hallmark of NETs in general, are that they are relatively slow growing and less invasive in character. Thus, its interesting to note that several genes thought to play a role in the processes of invasion, tumour progression and metastasis (MME, STAT3, DCBLD2, S100A10, CD9, S100A8) were highly downregulated in the NE $v s$ the non-NE tumour group (Table 2). The most highly downregulated gene was MME. A loss or decrease in MME has been reported in a variety of malignancies, and reduced expression results in the accumulation of higher peptide concentrations that could mediate neoplastic progression (Sumitomo et al, 2005). Loss of this endopeptidase also leads to AKT1 (protein kinase B) activation, and contributes to the clinical progression of prostate cancer (Osman et al, 2006). STAT3 (the signal-transducer and activator - of transcription 3 ) is thought to play an important role in both tumorigenesis and tumour progression, and is often constitutively activated in tumour cells (Aggarwal et al, 2006). Thus, inhibitors of STAT3 activation have potential for both prevention and therapy of cancer (Huang, 2007). In lung cancer, $D C B L D 2$ has been shown to be highly upregulated in the cell line NCI-H460-LNM35, in association with its acquisition of metastatic phenotype, and also upregulated in high frequency in metastatic lesions from lung cancers (Koshikawa et al, 2002). It is also shown that DCBLD2 may play a role in cell motility (Nagai et al, 2007), and thus it is suggested that this novel gene may become a target of therapy to inhibit metastasis of lung cancers.

The plasminogen receptor S100A10 is found overexpressed in many cancer cells, and seems to play an important role in cancer cell invasiveness and metastasis (Kwon et al, 2005). RNA interference-mediated downregulation of S100A10 gene expression in colorectal cancer cells, has been shown to result in a complete loss in plasminogen-dependent cellular invasiveness (Zhang et al, 2004). More recently it has been shown by IHC analysis that S100A10 expression in thyroid neoplasms contributes to the aggressive characteristic of anaplastic carcinoma (Ito et al, 2007). To conclude, the very low levels of various genes known to be involved in the processes of invasion, tumour progression and metastasis could perhaps reflect the in general more slow growing and less invasive character of NETs.

In addition to the already mentioned STAT3 and PRXD2, other genes that have been linked to the phenomenon of drug resistance, 
were identified as differentially expressed (ABCC6, GSTP1). Welldifferentiated NETs are in general relatively insensitive to various chemotheurapeutic drugs. Thus, it is interesting to note that our study reveals a relatively high expression of ABCC6 (ATP-binding cassette, subfamily $\mathrm{C}$ (CFTR/MRP), member 6), one member of the MRP subfamily involved in multi-drug resistance (Beck et al, 2005). Endocrine G-cells in the stomach has been shown to express high level of ABCC6 (Beck et al, 2005). However, our study is the first to report ABCC6 expression in NE tumour cells. The antiapoptosis gene GSTP1, was highly downregulated in the NET group (Table 2). In prostate cancer, the loss of expression of GSTP1 is the most common genetic alteration reported (Meiers et al, 2007). A comprehensive survey of GSTP1 expression in NETs has so far not been performed, but one study has been undertaken, showing that the expression of this drug-resistant protein is significantly lower in large cell NE carcinoma of the lung than in the other more common histological types of lung cancer (Okada et al, 2003).

In conclusion, the results of our study add new important lights into the understanding of NE tumour biology, by identifying genes differentially expressed in NE as compared with non-NE tumour cells. In addition to potential new diagnostic markers (SCG2, SCG3, DDC, MAOA, NEFM, CLDN4, PEROX2), genes critical in the processes of tumour invasion, progression and metastasis $(M M E$, STAT3, DCBLD2, S100A10, CD9, S100A8), tumorigenesis (BEX1, TMEPAI, FOSL1, RAB32) and drug-resistance (ABCC6, GSTP1)

\section{REFERENCES}

Aggarwal BB, Sethi G, Ahn KS, Sandur SK, Pandey MK, Kunnumakkara AB, Sung B, Ichikawa H (2006) Targeting signal-transducer-and-activator-oftranscription-3 for prevention and therapy of cancer: modern target but ancient solution. Ann N Y Acad Sci 1091: $151-169$

Alvarez E, Zhou W, Witta SE, Freed CR (2005) Characterization of the Bex gene family in humans, mice, and rats. Gene 357: 18-28

Baldus CD, Martus $\mathrm{P}$, Burmeister T, Schwartz S, Gokbuget $\mathrm{N}$ Bloomfield CD, Hoelzer D, Thiel E, Hofmann WK (2007) Low ERG and BAALC expression identifies a new subgroup of adult acute T-lymphoblastic leukemia with a highly favorable outcome. J Clin Oncol 25: $3739-3745$

Beck K, Hayashi K, Dang K, Hayashi M, Boyd CD (2005) Analysis of ABCC6 (MRP6) in normal human tissues. Histochem Cell Biol 123: $517-528$

Bozzi F, Luksch R, Collini P, Gambirasio F, Barzano E, Polastri D, Podda M, Brando B, Fossati-Bellani F (2004) Molecular detection of dopamine decarboxylase expression by means of reverse transcriptase and polymerase chain reaction in bone marrow and peripheral blood: utility as a tumor marker for neuroblastoma. Diagn Mol Pathol 13: $135-143$

Brazma A, Hingamp P, Quackenbush J, Sherlock G, Spellman P, Stoeckert C, Aach J, Ansorge W, Ball CA, Causton HC, Gaasterland T, Glenisson P, Holstege FC, Kim IF, Markowitz V, Matese JC, Parkinson H, Robinson A, Sarkans U, Schulze-Kremer S, Stewart J, Taylor R, Vilo J, Vingron M (2001) Minimum information about a microarray experiment (MIAME)toward standards for microarray data. Nat Genet 29: 365-371

Capella C, La Rosa S, Uccella S, Billo P, Cornaggia M (2000) Mixed endocrine-exocrine tumours of the gastrointestinal tract. Semin Diagn Pathol 17: $91-103$

DeLellis RA (2001) The neuroendocrine system and its tumors: an overview. Am J Clin Pathol 115(Suppl): S5-S16

Evers BM, Townsend Jr CM, Upp JR, Allen E, Hurlbut SC, Kim SW, Rajaraman S, Singh P, Reubi JC, Thompson JC (1991) Establishment and characterization of a human carcinoid in nude mice and effect of various agents on tumor growth. Gastroenterology 101: 303-311

Falkmer S (1993) Phylogeny and ontogeny of the neuroendocrine cells of the gastrointestinal tract. Endocrinol Metab Clin North Am 22: $731-752$

Foltz G, Ryu GY, Yoon JG, Nelson T, Fahey J, Frakes A, Lee H, Field L, Zander K, Sibenaller Z, Ryken TC, Vibhakar R, Hood L, Madan A (2006) Genome-wide analysis of epigenetic silencing identifies BEX1 and BEX2 were identified, as well as several genes with hitherto unknown functions.

\section{ACKNOWLEDGEMENTS}

This work was supported by the Norwegian Foundation for Health and Rehabilitation, The Norwegian Cancer Society, The Norwegian Research Council and the Cancer Fund at the St Olavs Hospital HF, Trondheim. We gratefully acknowledge the advice given by professor Ursula Falkmer, Oncology Unit, St Olavs Hospital HF, Trondheim, Norway, and professor Sture Falkmer, Department of Laboratory Medicine, Faculty of Medicine, Norwegian University of Science and Technology, Trondheim for advise and help with the characterisation of the cell lines used. Furthermore, we thank Kåre E Tvedt, PhD, Associate Professor of Morphology, and Head of the Electron Microscopy Unit of St Olavs University Hospital, Department of Laboratory Medicine, Faculty of Medicine, Norwegian University of Science and Technology, Trondheim, for his excellent assistance in the ultra structural investigations. We also thank Ole Jonny Steffensen, Department of pathology, Ålesund Hospital, Ålesund, Norway, for help with the IHC analysis.

Supplementary Information accompanies the paper on British Journal of Cancer website (http://www.nature.com/bjc) as candidate tumor suppressor genes in malignant glioma. Cancer Res 66: $6665-6674$

Giannini G, Ambrosini MI, Di Marcotullio L, Cerignoli F, Zani M, MacKay AR, Screpanti I, Frati L, Gulino A (2003) EGF- and cell-cycle-regulated STAG1/PMEPA1/ERG1.2 belongs to a conserved gene family and is overexpressed and amplified in breast and ovarian cancer. Mol Carcinog 38: $188-200$

Guillemot J, Barbier L, Thouennon E, Vallet-Erdtmann V, MonteroHadjadje M, Lefebvre $H$, Klein M, Muresan M, Plouin PF, Seidah N, Vaudry H, Anouar Y, Yon L (2006) Expression and processing of the neuroendocrine protein secretogranin II in benign and malignant pheochromocytomas. Ann N Y Acad Sci 1073: 527-532

Hofsli E (2006) Genes involved in neuroendocrine tumour biology. Pituitary 9: $165-178$

Hofsli E, Thommesen L, Yadetie F, Langaas M, Kusnierczyk W, Falkmer U, Sandvik AK, Laegreid A (2005) Identification of novel growth factorresponsive genes in neuroendocrine gastrointestinal tumour cells. Br J Cancer 92: $1506-1516$

Hsieh AC, Moasser MM (2007) Targeting HER proteins in cancer therapy and the role of the non-target HER3. Br J Cancer 97: 453-457

Huang S (2007) Regulation of metastases by signal transducer and activator of transcription 3 signaling pathway: clinical implications. Clin Cancer Res 13: $1362-1366$

Ito Y, Arai K, Nozawa R, Yoshida H, Higashiyama T, Takamura Y, Miya A, Kobayashi K, Kuma K, Miyauchi A (2007) S100A10 expression in thyroid neoplasms originating from the follicular epithelium: contribution to the aggressive characteristic of anaplastic carcinoma. Anticancer Res 27: $2679-2683$

Kominsky SL, Tyler B, Sosnowski J, Brady K, Doucet M, Nell D, Smedley III JG, McClane B, Brem H, Sukumar S (2007) Clostridium perfringens enterotoxin as a novel-targeted therapeutic for brain metastasis. Cancer Res 67: 7977 - 7982

Koshikawa K, Osada H, Kozaki K, Konishi H, Masuda A, Tatematsu Y, Mitsudomi T, Nakao A, Takahashi T (2002) Significant up-regulation of a novel gene, CLCP1, in a highly metastatic lung cancer subline as well as in lung cancers in vivo. Oncogene 21: 2822-2828

Kothapalli R, Yoder SJ, Mane S, Loughran Jr TP (2002) Microarray results: how accurate are they? BMC Bioinformatics 3: 22

Kwon M, MacLeod TJ, Zhang Y, Waisman DM (2005) S100A10, annexin A2, and annexin a2 heterotetramer as candidate plasminogen receptors. Front Biosci 10: $300-325$ 
Langaas M (2005) Estimating the proportion of true null hypotheses, with application to DNA microarray data. J R Stat Soc 67: 555-572

Lee W, Choi KS, Riddell J, Ip C, Ghosh D, Park JH, Park YM (2007) Human peroxiredoxin 1 and 2 are not duplicate proteins: the unique presence of CYS83 in Prx1 underscores the structural and functional differences between Prx1 and Prx2.J Biol Chem 282: 22011-22022

Livak KJ, Schmittgen TD (2001) Analysis of relative gene expression data using real-time quantitative PCR and the 2(-Delta Delta C(T)) Method. Methods 25: $402-408$

Marcucci G, Mrozek K, Bloomfield CD (2005) Molecular heterogeneity and prognostic biomarkers in adults with acute myeloid leukemia and normal cytogenetics. Curr Opin Hematol 12: 68-75

Meiers I, Shanks JH, Bostwick DG (2007) Glutathione S-transferase pi (GSTP1) hypermethylation in prostate cancer: review 2007. Pathology 39: $299-304$

Moldvay J, Jackel M, Paska C, Soltesz I, Schaff Z, Kiss A (2007) Distinct claudin expression profile in histologic subtypes of lung cancer. Lung Cancer 57: $159-167$

Morin PJ (2005) Claudin proteins in human cancer: promising new targets for diagnosis and therapy. Cancer Res 65: 9603-9606

Murthy R, Erlandsson K, Kumar D, Van Heertum R, Mann J, Parsey R (2007) Biodistribution and radiation dosimetry of 11C-harmine in baboons. Nucl Med Commun 28: 748 - 754

Nagai H, Sugito N, Matsubara H, Tatematsu Y, Hida T, Sekido Y, Nagino M, Nimura Y, Takahashi T, Osada H (2007) CLCP1 interacts with semaphorin $4 \mathrm{~B}$ and regulates motility of lung cancer cells. Oncogene 26: $4025-4031$

Nørsett KG, Laegreid A, Midelfart H, Yadetie F, Erlandsen SE, Falkmer S, Grønbech JE, Waldum HL, Komorowski J, Sandvik AK (2004) Gene expression based classification of gastric carcinoma. Cancer Lett 210: $227-237$

Okada D, Kawamoto M, Koizumi K, Tanaka S, Fukuda Y (2003) Immunohistochemical study of the expression of drug-resistant proteins in large cell neuroendocrine carcinoma of the lung. Jpn J Thorac Cardiovasc Surg 51: 272-276

Örlefors H, Sundin A, Fasth KJ, Berg K, Langstrom B, Eriksson B, Bergstrom M (2003) Demonstration of high monoaminoxidase-A levels in neuroendocrine gastroenteropancreatic tumors in vitro and in vivotumor visualization using positron emission tomography with 11Charmine. Nucl Med Biol 30: 669-679

Osman I, Dai J, Mikhail M, Navarro D, Taneja SS, Lee P, Christos P, Shen R, Nanus DM (2006) Loss of neutral endopeptidase and activation of protein kinase $\mathrm{B}$ (Akt) is associated with prostate cancer progression. Cancer 107: $2628-2636$

Perez MA, Saul SH, Trojanowski JQ (1990) Neurofilament and chromogranin expression in normal and neoplastic neuroendocrine cells of the human gastrointestinal tract and pancreas. Cancer 65: $1219-1227$

Qvigstad G, Falkmer S, Westre B, Waldum HL (1999) Clinical and histopathological tumour progression in ECL cell carcinoids ('ECLomas'). APMIS 107: $1085-1092$

R Development Core Team (2004) R: A Language and Environment for Statistical Computing. InR Foundation for Statistical Computing Vienna: Austria, ISBN 3-900051-00-3 http://www.r-project.org

Shibata D, Mori Y, Cai K, Zhang L, Yin J, Elahi A, Hamelin R, Wong YF, Lo WK, Chung TK, Sato F, Karpeh Jr MS, Meltzer SJ (2006) RAB32 hypermethylation and microsatellite instability in gastric and endometrial adenocarcinomas. Int J Cancer 119: 801-806

Smyth GK (2005) Limma: linear models for microarray data. In Bioinformatics and Computational Biology Solutions using $R$ and Bioconductor, Gentleman R, Carey V, Dudoit S, Irizarry R \& Huber W (eds), pp 397-420. Springer: New York
Smyth GK, Michaud J, Scott H (2005) The use of within-array replicate spots for assessing differential expression in microarray experiments. Bioinformatics 21: 2067-2075

Sørhaug S, Steinshamn S, Haaverstad R, Nordrum IS, Martinsen TC, Waldum HL (2007) Expression of neuroendocrine markers in non-small cell lung cancer. APMIS 115: $152-163$

Stephenson TJ (2006) Prognostic and predictive factors in endocrine tumours. Histopathology 48: 629-643

Storey JD (2002) A direct approach to false discovery rates. J Royal Stat Soc 64: $479-498$

Sumitomo M, Shen R, Nanus DM (2005) Involvement of neutral endopeptidase in neoplastic progression. Biochim Biophys Acta 1751: 52-59

Tanner SM, Austin JL, Leone G, Rush LJ, Plass C, Heinonen K, Mrozek K, Sill H, Knuutila S, Kolitz JE, Archer KJ, Caligiuri MA, Bloomfield CD, de La Chapelle A (2001) BAALC, the human member of a novel mammalian neuroectoderm gene lineage, is implicated in hematopoiesis and acute leukemia. Proc Natl Acad Sci USA 98: 13901-13906

Taupenot L, Harper KL, O'Connor DT (2003) The chromograninsecretogranin family. $N$ Engl J Med 348: $1134-1149$

Toninello A, Pietrangeli P, De Marchi U, Salvi M, Mondovi B (2006) Amine oxidases in apoptosis and cancer. Biochim Biophys Acta 1765: 1-13

Uccella S, Cerutti R, Vigetti D, Furlan D, Oldrini R, Carnevali I, Pelosi G, La Rosa S, Passi A, Capella C (2006) Histidine decarboxylase, DOPA decarboxylase, and vesicular monoamine transporter 2 expression in neuroendocrine tumors: immunohistochemical study and gene expression analysis. J Histochem Cytochem 54: 863-875

Ueda J, Semba S, Chiba H, Sawada N, Seo Y, Kasuga M, Yokozaki H (2007) Heterogeneous expression of claudin- 4 in human colorectal cancer: decreased claudin- 4 expression at the invasive front correlates cancer invasion and metastasis. Pathobiology 74: $32-41$

Vilar E, Salazar R, Perez-Garcia J, Cortes J, Oberg K, Tabernero J (2007) Chemotherapy and role of the proliferation marker Ki-67 in digestive neuroendocrine tumors. Endocr Relat Cancer 14: 221-232

Wafa LA, Palmer J, Fazli L, Hurtado-Coll A, Bell RH, Nelson CC, Gleave ME, Cox ME, Rennie PS (2007) Comprehensive expression analysis of L-dopa decarboxylase and established neuroendocrine markers in neoadjuvant hormone-treated $v s$ varying Gleason grade prostate tumors. Hum Pathol 38: $161-170$

Wick MR (2000) Neuroendocrine neoplasia. Current concepts. Am J Clin Pathol 113: $331-335$

Xu LL, Shi Y, Petrovics G, Sun C, Makarem M, Zhang W, Sesterhenn IA, McLeod DG, Sun L, Moul JW, Srivastava S (2003) PMEPA1, an androgenregulated NEDD4-binding protein, exhibits cell growth inhibitory function and decreased expression during prostate cancer progression. Cancer Res 63: 4299-4304

Yadetie F, Laegreid A, Bakke I, Kusnierczyk W, Komorowski J, Waldum HL, Sandvik AK (2003) Liver gene expression in rats in response to the peroxisome proliferator-activated receptor-alpha agonist ciprofibrate. Physiol Genomics 15: 9-19

Yang QS, Xia F, Gu SH, Yuan HL, Chen JZ, Yang QS, Ying K, Xie Y, Mao YM (2002a) Cloning and expression pattern of a spermatogenesisrelated gene, BEX1, mapped to chromosome Xq22. Biochem Genet 40: 1- 12

Yang YH, Dudoit S, Luu P, Lin DM, Peng V, Ngai J, Speed TP (2002b) Normalization for cDNA microarray data: a robust composite method addressing single and multiple slide systematic variation. Nuclei Acids Res 30: e15

Young MR, Colburn NH (2006) Fra-1 a target for cancer prevention or intervention. Gene 379: 1-11

Zhang L, Fogg DK, Waisman DM (2004) RNA interference-mediated silencing of the S100A10 gene attenuates plasmin generation and invasiveness of Colo 222 colorectal cancer cells. J Biol Chem 279: $2053-2062$ 